\title{
Distal Common Bile Duct
}

National Cancer Institute

\section{Source}

National Cancer Institute. Distal Common Bile Duct. NCI Thesaurus. Code C60801.

The section of the tube-like structure carrying bile that is closest to the intestine and furthest from the hepatic and cystic ducts. 